\title{
Sinus Surgery in Children: Trends in Kosovo over a Nine Year Period
}

\section{Emina Ramku*, Adem Limani, Qazim.Hysenaj, Refik Ramku and Valbona Zhjeq}

Department of ENT, Prishtina University Clinical Center, University of Prishtina, Prishtinë, Kosovo

\begin{abstract}
Aim: The paranasal sinuses are a common site of infection in children and adolescents and are associated with frequent morbidity. Rarely, life-threatening complications occur. The aim of this study was to investigate cases of sinus complications in children treated over the last nine years at the University Clinical Center, ENT Clinic, in Pristina, Kosovo.

Methods: The total number of sinus complication was 56. Based on Chandler's classification, the most frequent was group I, with palpebral inflammatory edema (27 cases), while the most infrequent was group V, with only one case of septic thrombosis of the cavernous sinus. Children with sinusitis with complications had markedly higher CRP levels (median: $10.05 \mathrm{mg} / \mathrm{dL}$ ) and ESRs (median: $67 \mathrm{~mm} / \mathrm{h}$ ) than those with uncomplicated sinusitis (median CRP: 0.8 $\mathrm{mg} / \mathrm{dL}$; median ESR: $7 \mathrm{~mm} / \mathrm{h}$ ).
\end{abstract}

Results: Six children underwent sinus surgery and 50 were treated with medications $(p<0.01)$; there were 21 females and 35 males among the study subjects $(p>0.05)$. Three of the children had more than one sinus infection $(p>0.05)$. Of the 56 cases with sinus complications, $9.3 \%$ had nasal polyposis.

Conclusions: Sinus complication surgery in children is decreasing in Kosovo not only because of treatment with aggressive antibiotic therapy, but also because of primary surgical interventions such as septoplasty, adenoidectomy and nasal polypectomy.

Keywords: Sinus complications; Antibiotic therapy; Surgical intervention

\section{Introduction}

The ethmoid and maxillary sinuses are formed in the third to fourth gestational month and accordingly, are present at birth (Figure 1). It can be difficult to distinguish children with uncomplicated viral upper respiratory infections or adenoiditis from those with an episode of acute bacterial sinusitis. Most viral infections of the upper respiratory tract involve the nose and paranasal sinuses (viral rhinosinusitis) [1]. However, bacterial infections of the paranasal sinuses do not usually involve the nose. When a patient with a bacterial infection of the paranasal sinuses has purulent (thick, colored, and opaque) nasal drainage, the site of infection is likely the paranasal sinuses; the nose is merely acting as a conduit for the secretions produced there. Acute bacterial sinusitis is a bacterial infection of the paranasal sinuses lasting fewer than 30 days, during which time the symptoms resolve completely. Sub-acute bacterial sinusitis is a bacterial infection of the paranasal sinuses lasting 30-90 days, during which time the symptoms resolve completely. Recurrent acute bacterial sinusitis is characterized by episodes of bacterial infection of the paranasal sinuses, each lasting fewer than 30 days and separated by intervals of at least 10 days, during which time the patient is asymptomatic. Chronic sinusitis is characterized by episodes of inflammation of the paranasal sinuses lasting for more than 90 days. Patients have persistent residual respiratory symptoms, including a cough, rhinorrhea, or nasal obstruction.

\section{Materials and Methods}

In this report, we describe 56 patients who were treated at the University Clinical Center, ENT Clinic, in Pristina, Kosovo. Six of the patients underwent sinus surgery while the other 50 were treated with medications. Preparation for all cases included:

- X-rays of the sinuses. In all cases, we had positive findings of sinusitis.

- CT scan, axial and coronal imaging.

- Blood analyses and microbiological findings (CRP, ESRs, and white blood cells).
- Allergen testing with 30 allergens was conducted in $35 \%$ of all cases of sinusitis with complications (only five cases were positive for inhalator antigens).

- Ophthalmological examinations; we found no loss of vision in any of the 56 cases [2].

- Based on Chandler's classification, the most frequent was group I, with 27 cases of palpebral inflammatory edema, while
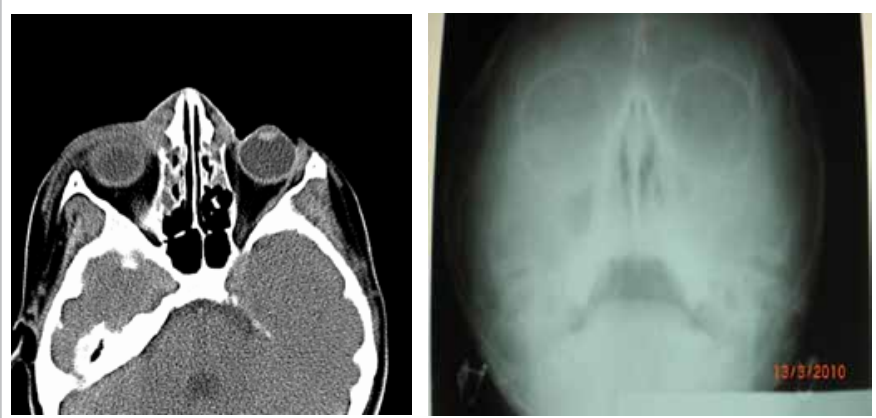

Figure 1: Sinus complications and nasal polyposis as revealed by $C$ and $\mathrm{X}$-ray images in the right nasal cavity of a 12 -year-old conservativelytreated female. In the CT image, edema of the palpebrae and the presence of secretions in the ethmoid sinus can be seen clearly. In the X-ray of the same patient, secretions in the frontal, ethmoidal and maxillary sinuses can be detected, as can orbital cellulitis in the right eye.

*Corresponding author: Emina Ramku, ENT specialist, Department of ENT, Prishtina University Clinical Center, University of Prishtina, Prishtinë, Kosovo, Tel: 044-298-244; E-mail: minkaramku@hotmail.com

Received December 15, 2012; Accepted January 25, 2013; Published February 03, 2013

Citation: Ramku E, Limani A, Hysenaj Q, Ramku R, Zhjeqi V (2013) Sinus Surgery in Children: Trends in Kosovo over a Nine Year Period. Surgery S12: 004 doi:10.4172/2161-1076.S12-004

Copyright: $\odot 2013$ Ramku E, et al. This is an open-access article distributed under the terms of the Creative Commons Attribution License, which permits unrestricted use, distribution, and reproduction in any medium, provided the original author and source are credited. 
the most infrequent was group $\mathrm{V}$, with only one case of septic thrombosis of the cavernous sinus. There were 25 cases with orbital cellulitis, two with orbital subperiosteal abscesses, and three with retrobulbar abscesses. In three cases, we opened only one sinus while in the other three cases more than one sinus was opened. Of these patients, $64 \%$ had primary nasal infections and $9 \%$ had nasal polyposis.

\section{Results}

A total of 366 children with uncomplicated sinusitis in the same healthcare system were treated as outpatients with medications. The total number of patients with sinus complications was 56; of these, 21 were female and 31 were male (Table 1). 6 underwent sinus surgery and 50 were treated with medications. In 2004, there were eight cases; in 2005, one case was treated with surgery and one with medications; in 2008, there were four cases, one treated with surgery and three with conservative treatments; and in 2006, there were seven, one treated with surgery and six with conservative treatments (Table 2). The first group was comprised of ten children with sinus complication, aged 2-7 years. The second group consisted of 16 children, 8-12 years old. The third group was composed of 30 children, 13-18 years old (Table 3 ). In total, 21 of the children were females and 35 were males $(62.5 \%)$. The year with the most cases was 2011 (15 cases (27\%)). All children were treated with antibiotics (amoxicillin or ceftriaxone) because the microbiological findings indicated Gram-positive bacteria; in particular, 29\% of the cases involved Staphylococcus aureus (Table 6). The median period of hospitalization for the six patients undergoing surgery was 21 days; the median for conservative treatment was 10.5 days. Three of the children had an infection of more than one sinus, orbital cellulitis, and retro-orbital abscesses. The other three had only one sinus infection plus orbital cellulitis and retro-orbital abscesses. Based on Chandler's classification, the most frequent was group I, with 27 cases of palpebral inflammatory edema, while the most infrequent was group $\mathrm{V}$, with only one case of septic thrombosis of the cavernous sinus. There were 25 cases with orbital cellulitis, two with orbital subperiosteal abscesses, and three with retrobulbar abscesses (Table 5). In three cases, we opened only one sinus while in the other three cases more than one sinus was opened (Table 4).

The bacterium most commonly isolated was $S$. aureus (16 cases, $29 \%)$, followed by Streptococcus hemolyticus ( $\beta$ ) and Branhamella catarrhalis. No microbiological result was found in $35 \%$ of the cases. Those patients with complications had markedly higher CRP levels (median: $10.5 \mathrm{mg} / \mathrm{dL}$ ) and ESRs (median: $89 \mathrm{~mm} / \mathrm{h}$ ).

16.07 of them were with deviation septi nasi and 893 were with nasal polyposis [3].

\begin{tabular}{|l|c|c|c|c|}
\hline Year & Females & Males & Total & $\%$ \\
\hline 2003 & 2 & 2 & 4 & 7.14 \\
\hline 2004 & 4 & 4 & 8 & 14.29 \\
\hline 2005 & 0 & 2 & 2 & 3.57 \\
\hline 2006 & 0 & 1 & 1 & 1.79 \\
\hline 2007 & 2 & 4 & 6 & 10.71 \\
\hline 2008 & 2 & 2 & 4 & 7.14 \\
\hline 2009 & 3 & 4 & 7 & 12.50 \\
\hline 2010 & 2 & 7 & 9 & 16.07 \\
\hline 2011 & 5 & 10 & 15 & 26.79 \\
\hline Total & 21 & 35 & 56 & 100.00 \\
\hline$\%$ & 37.5 & 62.5 & 100 & \\
\hline$X^{2}$ & 3.50 & & & \\
\hline$p>0.05$ & & & & \\
\hline
\end{tabular}

Table 1: Sinusogenic complications in the children by sex.

\begin{tabular}{|l|c|c|c|c|}
\hline Year & Surgery & Medicament treatment & Total & $\%$ \\
\hline 2003 & 0 & 4 & 4 & 7.14 \\
\hline 2004 & 3 & 5 & 8 & 14.29 \\
\hline 2005 & 1 & 1 & 2 & 3.57 \\
\hline 2006 & 0 & 1 & 1 & 1.79 \\
\hline 2007 & 0 & 6 & 6 & 10.71 \\
\hline 2008 & 1 & 3 & 4 & 7.14 \\
\hline 2009 & 1 & 6 & 7 & 12.50 \\
\hline 2010 & 0 & 9 & 9 & 16.07 \\
\hline 2011 & 0 & 15 & 15 & 26.79 \\
\hline Total & 6 & 50 & 56 & 100.00 \\
\hline$\%$ & 10.71 & 89.29 & 100 & \\
\hline$X^{2}$ & 34.57 & & & \\
\hline$p<0.01$ & & & & \\
\hline
\end{tabular}

Table 2: Sinusogenic complications in the children by method of treatment.

\begin{tabular}{|l|c|c|}
\hline Age group & Cases & $\%$ \\
\hline $2-7$ & 10 & 17.86 \\
\hline $8-12$ & 16 & 28.57 \\
\hline $13-18$ & 30 & 53.57 \\
\hline Total & 56 & 100.00 \\
\hline
\end{tabular}

Table 3: Sinusogenic complications in the children by age.

\begin{tabular}{|l|c|c|c|}
\hline CT and X-ray findings & One sinus & More than one sinus & $\%$ \\
\hline Surgically treated & 3 & 3 & 12 \\
\hline Conservatively treated & 30 & 20 & 88 \\
\hline$X^{2}$ & 0.001 & & \\
\hline$p>0.05$ & & & \\
\hline
\end{tabular}

Table 4: Sinusogenic complications in the children by method of diagnosis.

\begin{tabular}{|l|c|l|}
\hline $\begin{array}{l}\text { Pathology according to } \\
\text { Chandler's classification }\end{array}$ & Cases & \multicolumn{1}{|c|}{ Treatment } \\
\hline Palpebral inflammatory edema & 27 & Intensive antibiotic therapy \\
\hline Orbital cellulitis & 25 & Intensive antibiotic therapy \\
\hline Orbital subperiosteal abscess & 2 & Surgery + intensive antibiotic therapy \\
\hline Retrobulbar abscess & 3 & Surgery + intensive antibiotic therapy \\
\hline $\begin{array}{l}\text { Septic thrombosis of the } \\
\text { cavernous sinus }\end{array}$ & 1 & Surgery + intensive antibiotic therapy \\
\hline
\end{tabular}

Table 5: Cases and treatments based on Chandler's classification.

\begin{tabular}{|l|c|c|}
\hline Type of bacteria & Cases & $\%$ \\
\hline Staphylococcus aureus & 16 & 28.57 \\
\hline $\begin{array}{l}\text { Streptococcus } \\
\text { hemolyticus }(\beta)\end{array}$ & 14 & 25.00 \\
\hline Branhamella catarrhalis & 6 & 10.71 \\
\hline No result found & 20 & 35.71 \\
\hline Total & 56 & 100.00 \\
\hline
\end{tabular}

Table 6: Sinusogenic complications in the children by microbiological findings.

\section{Discussion}

Correlations were examined between the clinical, radiographic, and bacteriological findings in 30 children with maxillary sinusitis who had both upper respiratory tract symptoms and abnormal maxillary radiographs. Cough, nasal discharge, and fetid breath were the most common signs; fever was present inconsistently. Facial pain or swelling and headache were prominent symptoms in the older children. Bacterial colony counts of $\geq 10^{4}$ colony forming units per $\mathrm{ml}$ were found in 34 of 47 sinus aspirates from 23 children. The most common species recovered were Streptococcus pneumoniae, Haemophilus influenzae and $B$. catarrhalis. No anaerobic bacterium was isolated. Viruses were isolated from only two sinus aspirates. There was a poor 
correlation between the predominant species of bacteria recovered from the nasopharyngeal or throat culture and the bacteria isolated from the sinus aspirate. Thus, this study demonstrates that children with both upper respiratory tract symptoms and abnormal sinus radiographs are likely to harbor bacteria in their sinuses, suggesting that such children have bacterial sinusitis [4]. The clinical features and diagnostic and prognostic values of Systemic Inflammatory Response Syndrome (SIRS) were studied in 158 children with rhino-sinusogenic orbital and intracranial complications (Chart 1). Patients with more severe conditions showed a greater number of SIRS markers and required surgical removal of the primary infectious process in the paranasal sinuses more often (31\%). Increased SIRS symptoms led to an increase in organic dysfunction, from 3.3 to $53.3 \%$. The main targets for shock are the brain and meninges, with the lungs often being a secondary target and the hemostasis system also often being involved. Complicated rhinosinusitis should be regarded as septic if, in addition to the primary infectious process, the child has two or more SIRS symptoms and signs of organic dysfunction [5].

This approach to the diagnosis and treatment of sepsis has led to the recovery of $98.5 \%$ of children with this condition [6]. In our study, the bacterium most commonly isolated was $S$. aureus (16 cases, $29 \%$ ), followed by $S$. hemolyticus $(\beta)$ and B. catarrhalis. In a previous study, demographic, microbiological and outcomes data were assessed for children with complications of acute sinusitis [7]. In a retrospective review of 104 children admitted with complications of acute sinusitis from January 1995 to July 2002 to a tertiary care children's hospital, the following complications were noted: orbital cellulitis (51), orbital abscesses (44), epidural empyemas (7), subdural empyemas (6), intracerebral abscesses (2), meningitis (2), cavernous sinus thrombosis (1) and Pott's puffy tumours (3). Of the children, $66 \%$ were males $(p<0.001)$, and $64.4 \%$ presented from November to March $(\mathrm{p}<0.001)$. Those patients with isolated orbital complications were younger than the patients with intracranial complications (mean, 6.5 vs. 12.3 years), had a shorter stay (mean, 4.2 vs. 16.6 days) and had a shorter duration of symptoms (mean, 5.4 vs. 14.3 days; all $\mathrm{p}<0.0001$ ). Complete resolution was documented for $54 / 55$ patients with restricted ocular motility, $7 / 8$ with visual loss, $3 / 3$ patients with a non-reactive pupil, $7 / 7$ with neurological deficits, and $2 / 4$ with seizures. The most common organism isolated was Streptococcus milleri (11 of 36 patients with surgical cultures). No death occurred, and persistent morbidity was seen in four patients $(3.8 \%)$. Streptococcus milleri is a common pathogen in complications of sinusitis in children [8]. In our study, based on Chandler's classification, the most frequent was group I, with palpebral inflammatory edema (27 cases), while the most infrequent was group $\mathrm{V}$, with only one case of septic thrombosis of the cavernous sinus. There were 25 cases with orbital cellulitis, two with orbital subperiosteal abscesses and three with retrobulbar abscesses. A retrospective review of children diagnosed and treated for suppurative complications of paranasal sinusitis was undertaken to describe the clinical presentation, microbiology and treatment [9]. This review included children with subgaleal abscesses and osteomyelitis of the frontal bone, subdural empyema, frontal lobe abscess, meningitis and encephalitis. Staphylococcus aureus and group $\mathrm{C} \beta$ hemolytic Streptococcus was commonly isolated agents. All children were treated with intravenous antibiotics, with drainage of both the sinus and extra cranial and intracranial suppurations. The results of treatment in this series support the opinion that combined aggressive surgical and antibiotic treatment is the preferred method for complicated sinusitis in children [9]. All of the children in our study were treated with antibiotics (amoxicillin or ceftriaxone) because the microbiological findings were indicative of Gram-positive bacteria and we achieved good results. Sinus complication surgery is decreasing in incidence

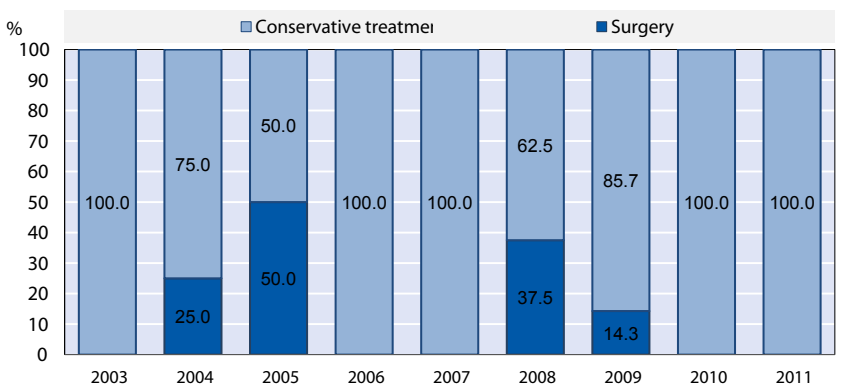

Chart 1: Sinusogenic complications in the children by method of treatment.

\begin{tabular}{|l|c|c|}
\hline Primary pathology & Number & $\%$ \\
\hline Deviation of nasal septum & 9 & 16.07 \\
\hline Primary nasal infection & 36 & 64.29 \\
\hline Hypertrophy of adenoids & 6 & 10.71 \\
\hline Allergies & 5 & 8.93 \\
\hline Nasal polyposis & 5 & 8.93 \\
\hline
\end{tabular}

Table 7: Primary pathology presenting with sinus complications in the children.

in Kosovo, not only because of treatment with aggressive antibiotic therapy but also because of primary surgical interventions in children, including septoplasty, adenoidectomy and nasal polypectomy.

\section{Conclusions}

Based on nine years of evaluation, we conclude that most cases of sinus infection in children can be managed without surgical intervention using high doses of antibiotics. When there are serious complications, combined aggressive surgical and antibiotic treatment is the preferred method. Sinus complication surgery is decreasing in incidence in Kosovo, not only because of treatment with aggressive antibiotic therapy but also because of primary surgical interventions in children [10] (Table 7), including septoplasty, adenoidectomy and nasal polypectomy.

\section{Acknowledgments, Grants and Technical Support}

We thank Dr. Adem Limani for his supervision of the research group and mentorship in my doctoral studies and Dr. Qazim Hysenaj, chief of the ENT department. We also thank Enver Mekolli and Dr. Valbona Zhjeqi for their assistance in collecting and analyzing data and in conducting the statistical analyses. We are also grateful for the moral support of my family.

\section{References}

1. Ueda D, Yoto $Y(1996)$ The ten-day mark as a practical diagnostic approach for acute paranasal sinusitis in children. Pediatr Infect Dis J 15: 576-579.

2. Fireman $P$ (1992) Diagnosis of sinusitis in children: emphasis on the history and physical examination. J Allergy Clin Immunol 90: 433-436.

3. Yung MW, Gould J, Upton GJ (2002) Nasal polyposis in children with cystic fibrosis: a long-term follow-up study. Ann Otol Rhinol Laryngol 111: 1081-1086.

4. Wald ER, Milmoe GJ, Bowen A, Ledesma-Medina J, Salamon N, et al. (1981) Acute maxillary sinusitis in children. N Engl J Med 304: 749-754.

5. Lusk RP, Stankiewicz JA (1997) Pediatric rhinosinusitis. Otolaryngol Head Neck Surg 117: S53-S57

6. Zinkin AN, Sergeev MM, Gornostaev AA (2003) Syndrome of systemic inflammatory response in children with septic pyogenic complications of rhinosinusitis. Anesteziol Reanimatol : 48-51.

7. Gwaltney JM Jr, Phillips CD, Miller RD, Riker DK (1994) Computed tomographic study of the common cold. N Engl J Med 330: 25-30.

8. McClay J, Oxford LE (2005) Complications of acute sinusitis in children. Otolaryngol Head Neck Surg 133: 32-37. 
Citation: Ramku E, Limani A, Hysenaj Q, Ramku R, Zhjeqi V (2013) Sinus Surgery in Children: Trends in Kosovo over a Nine Year Period. Surgery S12: 004. doi:10.4172/2161-1076.S12-004

9. Kuczkowski J, Narozny W, Mikaszewski B, Stankiewicz C (2005) Suppurative complications of frontal sinusitis in children. Clin Pediatr (Phila) 44: 675-682.
10. Aitken M, Taylor JA (1998) Prevalence of clinical sinusitis in young children followed up by primary care pediatricians. Arch Pediatr Adolesc Med 152: 244248 